\title{
Using Conversation Analysis for Examining Social Media Interactions
}

\author{
Matteo Farina ${ }^{\mathrm{a}, 1}$ \\ ${ }^{a}$ The University of Adelaide and Flinders University
}

\begin{abstract}
Social media research has grown exponentially in recent years. However, it seems that to date only a few studies have applied Conversation Analysis (CA) to study social media interactions. The aim of this paper is to show the benefits of using CA for the analysis of this type of social interactions.
\end{abstract}

Keywords. Conversation Analysis (CA), social media research, Facebook.

\section{Introduction}

In recent years many statisticians, mathematicians and computational scientists have turned their attention to social media research [1]. This has resulted in a huge amount of literature [2-6] that applied scientific approaches to analyze social media interactions. Although these studies identified the general patters that characterize these interactions, they did not analyze them from an interactional perspective. This paper tries to fill this gap in social media research. It proposes to use Conversation Analysis (CA) for the study of social media interactions. After a brief summary of the origins of CA and a discussion on why this methodological approach was used in the past for analyzing technology-mediated social interactions, this article discusses the case of @formulations in Facebook comment threads to show the benefits of using CA for social media research.

\section{Conversation Analysis}

\subsection{Origins}

Conversation Analysis (CA) is a methodological approach that studies social interactions [7-9]. It emerged in the late 1960s from the field of ethnomethodology through the work of Harvey Sacks, Emmanuel A. Schegloff and Gail Jefferson [10]. According to Sacks [7], people perform actions through talk. They can greet friends, request information, accept or decline invitations, ask questions and so on. Furthermore, actions performed through talk are interactionally achieved; they are the result of the collaborative work performed by participants in an interaction [7,9]. Thus, if a speaker wants to successfully perform a greeting, s/he may say "hello" to an intended recipient

${ }^{1}$ Corresponding Author, Matteo Farina, College of Humanities, Arts and Social Sciences, Flinders University, Bedford Park South Australia 5042; E-mail: alicematteo@gmail.com. 
and wait for a response. If the recipient fails to respond, the greeting is incomplete; only the First Pair Past (FPP) of an adjacency pair sequence has been performed, while a Second Pair Part (SPP) is missing [8]. This shows that actions accomplished through talk are organized in pairs, they are made up of two components, FPPs and SPPs; FPPs are turns at talk that launch sequences whereas SPPs are pieces of talk that complete sequences [8]. If one part is missing, the action is incomplete. Moreover, if like in the example above, a speaker utters a FPP and a recipient fails to produce a SPP, the action is not mutually achieved. Only one participant contributed to the interaction.

Although many scholars claim that CA is mainly suitable for investigating spoken conversation, this is not the case. Since its development, this methodological approach has been used for the examination of technology-mediated social interactions. For example, Schegloff used CA to study phone conversations [11]. This study describes the impact of the technology on the sequential organization of these interactions. It shows how the affordances and constrains of the telephone affect communications. This research also demonstrates that phone conversations are opened by identification and recognition sequences. These sequences are typical of phone conversations; they are used by conversationalists to identify their interlocutors. In telephone conversations people do not see each other; thus, participants use talk to overcome a limitation of the technology. Therefore, previous studies have pointed out that CA is a suitable approach for the examination of technology-mediated social interactions.

\subsection{CA and Computer-Mediated Communication}

With the introduction of the Internet in the 1980s social interactions became computerized. People started communicating with each other using Internet-Relay Chats (IRC)s, emails and online discussion forums [12]. In other words, everyday social interactions began to shift to digital environments. As a result, conversation analysts turned their attention to Computer-Mediated Communication (CMC). They studied synchronous as well as asynchronous interactions such as IRCs, discussion forums, weblogs and email exchanges [13-19]. They used CA to analyze the momentby-moment unfolding of computer-mediated interactions. Conversation analysts also examined the role of technology in CMC. They noticed that despite being either synchronous or asynchronous, computer-mediated communications are conversationallike. They are characterized by turn-taking [13, 14], repair [15] and sequential organization [19]. However, like phone conversations, the affordances and constraints of the technology have an impact on the interaction. For example, although turn-taking is identifiable in online chats, it is affected by the constraints of the platform used for communicating. Turn-taking was introduced by conversation analysts to describe what normally happens in spoken conversation, that is, that conversationalists speak one at a time. In other words, speakers do not talk simultaneously, when a speaker talks another listens and speaker changes occur with limited gaps and overlaps [7-9]. However, this is not the case in IRCs. In many IRCs systems, there is a delay between the processes of message production and message availability. Although messages that are published are immediately available to participants for inspection, messages that are being constructed are not available to participants. Therefore, there is a delay between the time in which a message is typed and when it is made available to recipients on screen. As a result, Garcia and Jacobs classified IRCs as quasi-synchronous [14]. More importantly, the delay between message construction and message availability affects the turn-taking system. That is, in online chats a participant might post a FPP that 
initiates a sequence, and before a recipient has posted a SPP that completes the pair, $\mathrm{s} /$ he might publish another FPP that launches another sequence. Thus, disrupting the linearity of the turn-taking system that establishes that FPPs and SPPs should be adjacently positioned one after another within adjacency pairs [7,9]. This disruption of the sequential organization of chat interactions is possible because of the affordances of the technology $[20,21]$. In other words, chat platforms allow adjacency pairs to be disrupted, which means that participants can post messages that start new sequences even before other participants have responded to them.

Therefore, CA is a powerful tool for the micro analysis of the moment-bymoment unfolding of CMC interactions. This approach enables researchers to reveal how sequentiality is achieved in computer-mediated communications. Moreover, it allows scholars to examine the role of the features of the technology in the interaction.

\subsection{Social Media as Loci for Social Interaction}

In recent years social media have become loci for social interaction [22]. 3.6 billion people use social media websites worldwide [23]; 2.5 billion are active on Facebook, 2.0 billion watch videos on YouTube and use WhatsApp, and 1.2 communicate on WeChat [24]. Individuals use social networking sites to communicate and maintain social relationships $[25,26]$. Moreover, as per phone conversations and other types of computer-mediated communications, interactions occurring on social media are conversational-like. Therefore, in the last few years, a growing number of studies has started applying CA to examine these interactions [27-34]. These studies have shown that interactions occurring on social media are multimodal, they consist of textual and visual elements such as texts, images, videos, hyperlinks as well as messages that are made up of the combinations of both these elements such as texts with images, texts with videos and texts with hyperlinks [27]. Moreover, social media interactions are sequentially organized. Facebook comment threads [28, 29] for instance, mainly consist of contributions that respond and orient to messages that launch comment threads. In other words, comments that follow an initial post generally respond to it, even when they are not adjacently positioned after this contribution. Thus, as per online chats, linearity does not seem to affect the sequential organization of Facebook comment threads. Nevertheless, Facebook users seem to successfully interpret and respond to comments even when they are not adjacently positioned one after the other in a comment thread. This depends on visual saliency [35], an affordance of many textbased communication systems. On Facebook, visual saliency enables users to access comments and create sequentiality. In other words, Facebook users can scroll comments up or down on screen to put FPPs and SPPs together and create sequences, regardless of their position in a comment thread.

The studies discussed in this and the previous paragraphs demonstrated that CA is a useful methodological approach for analyzing technology-mediated social interactions. They have shown that CA is fruitful to examine how "conversationalists" adapted their interactional practices to suit the affordances and constraints of the technology. The following section, on the other hand, will show that CA can also be used to prove that sometimes technologies have been modified to accommodate the interactional practices developed by their users. 


\section{3. @-formulations in Facebook interactions}

Facebook introduced the Reply button in 2013 [36]. This button is positioned under every comment posted in a comment thread (with the exception of the first comment in a thread) and allows users to respond to comments from Friends. In other words, this button enables Facebook users to post comments one after the other in a comment thread and achieve sequentiality. It appears that the Reply button was introduced to overcome a limitation of Facebook, that was that users did not have control over the positioning of comments within comment threads. Before the introduction of the Reply button, comments were organized in a chronological order; the last comment presented on screen was the most recent contribution published in a comment thread. So, when a user published a comment in a thread, $\mathrm{s} /$ he did not have control over its positioning in the interaction, this comment was always positioned as the last comment in the thread. This disrupted the sequentiality of interactions creating an interactional issue for Facebook users; they could not post a comment directly after the comment it was responding to. To overcome this limitation of the technology Facebook users started using@-formulations such as the @ symbol followed by a user's name (e.g. @Matteo Farina) to indicate to which comment they were responding to as clearly shown by extract 1 below:

Extract 1 [@-formulations in Facebook comment threads $]^{2}$

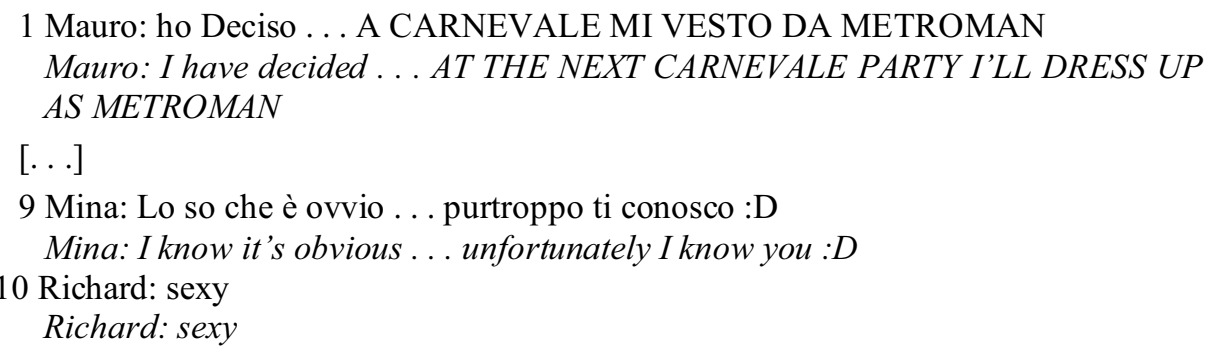

11 Daniele: @Mina: purtroppo ti conosco è un insulto gravissimo .... io non ti parlerei + a vita ;) @Mauro: io mi vesto da palo della metro, così puoi attaccarti al palo e girare!!!

Daniele: @Mina: unfortunately "I knowyou” is a terrible offence...I would feel like not talking to you anymore;) @Mauro: I will dress up as an underground pole, so you can attach yourself to the pole and swing around me!!!

Extract 1 is the transcript of a comment thread about Metroman, a busker who performs on the underground in Milan, Italy. After a series of comments [1-10] where Friends mock Mauro for humorously announcing his plan for the next Carnevale ${ }^{3}$ party, which is to dress up as Metroman, at comment 11 Daniele uses two@-formulations (@Mina;@Mauro) to select the recipients of his contribution. These @-formulations not only explicitly indicate the addressees of Daniele's comment but they also preserve the sequentiality of this comment thread. In other words, Daniele uses them to indicate to which comments he is responding to. The initial component of comment 11 clearly

\footnotetext{
${ }^{2}$ Please note that data in this extract have been transcribed and translated from Italian.

${ }^{3}$ Carnevale is an Italian celebration where people go to parties wearing masks and dressing up as fantasy characters, such as Pinocchio, Mickey Mouse, and so on.
} 
orients to the comment at Post 9, where Mina uses the expression "ti conosco" (I know you) to mock Mauro's plan of dressing up as Metroman. In this part of the comment, Daniele jokingly tells Mina that he considers "ti conosco" to be a terrible offence (@Mina: purtroppo ti conosco è un insulto gravissimo ... io non ti parlerei + a vita;)). On the other hand, the final component of the comment at Post 11 orients to Post 1. Daniele humorously says that if Mauro dresses up as Metroman, he will dress up as an underground pole, so Mauro can swing around him (@ Mauro: io mi vesto da palo della metro, cosi puoi attaccarti al palo e girare!!!). This comment refers to a video posted in another comment thread where Metroman swings around a pole while performing on the underground. Although occurring 10 comments after the contribution at post 1 , this message responds to it.

This analysis of Extract 1 shows that CA is a useful approach to demonstrate how technologies have sometimes been modified to suit the needs of their users.

\section{Conclusion}

This paper has demonstrated that CA is a useful approach for the investigation of social media interactions. This methodology enables researchers to make a fine-grained micro analysis of the moment-by-moment unfolding of these interactions. Furthermore, CA can be used to examine the role of the technology in social media interactions. This methodological approach can also reveal the interactional practices developed by social media users to overcome the limitations of the technology. In other words, CA provides researchers with an opportunity to study social media interactions from an interactional perspective. Therefore, this paper argues for the integration of CA into scientific research on social media. On one hand, this kind of interdisciplinary research might result in the development of more effective computational tools for social media interaction. On the other hand, it might be used for managing social problems; for instance, by creating softwares that detect posts that promote cyberhate and extremism in social media.

\section{References}

[1] Resnyansky L. Conceptual frameworks for social and cultural Big Data analytics: Answering the epistemological challenge. Big Data Society. 2019;6(1):1-12.

[2] Garton L, Haythornthwaite C, Wellman B. Studying online social networks. J Computer-Mediated Comm. 1997;3(1).

[3] O'Callaghan D, Greene D, Conway M, Carthy J, Cunningham P. An Analysis of interactions within and between extreme right communities in social media. Ubiquitous Social Media Analysis. 2012:88-107.

[4] Honey C, Herring CS. Beyond microblogging: Conversation and collaboration via Twitter. 2009 42nd Hawaii International Conference on System Sciences Ieee; 2009. p. 1-10.

[5] Ritter A, Cherry C, Dolan B. Unsupervised modeling of twitter conversations. Human Language Technologies: The 2010 Annual Conference of the North American Chapter of the Association for Computational Linguistics 2010:172-80.

[6] Weng J, Lim E-P, Jiang J, He Q, editors. Twitterrank: finding topic-sensitive influential twitterers. 3rd ACM international conference on Web search and data mining; 2010.

[7] Sacks H. Lectures on conversation. Jefferson G, editor. Cambridge: Blackwell Publishers; 1992.

[8] Sacks H, Schegloff E, Jefferson G. A simplest systematics for the organization of turn-taking for conversation. Language. 1974; 50(4): 696-735.

[9] Schegloff E. Sequence Organization in Interaction. Cambridge: Cambridge University Press; 2007. 
[10] Liddicoat AJ. An introduction to conversation analysis. London: Continuum International Publishing Group; 2011.

[11] Schegloff E. Identification and recognition in telephone conversation openings. In: Psathas G, editor. Everyday Language: Studies in ethnomethodology. New York: Irvington; 1979. p. 23-78.

[12] Giles D, Stommel W, Paulus T, Lester J, Reed D. Microanalysis of online data: the methodological development of "digital CA". Discourse, Context \& Media. 2015(7):45-51.

[13] Garcia CA, Jacobs BJ. The interactional organization of computer mediated communication in the college classroom. Qualitative Sociology. 1998;21(3):299-317.

[14] Garcia CA, Jacobs BJ. The eyes of the beholder: understanding the turn-taking system in quasisynchronous computer-mediated communication. Res. Language Social Inter. 1999; 33(4):337-67.

[15] Schönfeldt J, Golato A. Repair in chats: a conversation analytic approach. Res. Language Social Interaction. 2003; 36(3):241-84.

[16] Herring CS. A faceted classification scheme for computer-mediated discourse. Language@Internet. 2007;1(1):1-37.

[17] Herring CS. An approach to researching online behavior. In: Barab SA, Kling, Kling R, Gray JH, editors. Designing for Virtual Communities in the Service of Learning. New York: Cambridge University Press; 2004. p. 338-76.

[18] Antaki C, Ardévol E, Núñez F, Vayreda A. "For she who knows who she is:" Managing accountability in online forum messages. J Computer-Mediated Commun. 2005; 11(1):114,32.

[19] Reed D. 'Making Conversation': sequential integrity and the local management of interaction on internet newsgroups. Proceedings of the 34th Hawaii International Conference on System Sciences; Maui, Hawaii2001.

[20] Herring CS. Interactional Coherence in CMC. J Computer-Mediated Comm. 1999; 4(4).

[21] Berglund TÖ. Disrupted turn adjacency and coherence maintenance in instant messaging conversations. Language \& Internet. 2009;6(2):1-25.

[22] Golder S, Wilkinson D, Huberman B. Rhythms of social interaction: messaging within a massive online network. In: Steinfield C, Pentland BT, Ackerman M, Contractor N, editors. Communities and Technologies. London: Springer; 2007. p. 41-66.

[23] Clement J. Number of social network users worldwide from 2017 to 20252020 [cited 202022 July]. Available from: https:/www.statista.com/statistics/278414/number-of-worldwide-social-network-users/.

[24] Clement J. Most popular social networks worldwide as of April 2020, ranked by number of active users: Statista.com; 2020 [cited 2020 22 July]. Available from: https://www.statista.com/statistics/272014/global-social-networks-ranked-by-number-of-users/.

[25] Kabilan MK, Ahmad N, Abidin MJZ. Facebook: An online environment for learning of English in institutions of higher education? The Internet and Higher Education. 2010; 13: 179-87.

[26] Leonardi M. Narrative as self performance: the rhetorical construction of identities on Facebook profiles. Albuquerque: The University of Nex Mexico; 2009.

[27] Farina M. Facebook first post telling. Journal of pragmatics. 2015; 90:1-11.

[28] Farina M. Facebook and Conversation Analysis. London: Bloomsbury; 2018.

[29] Frobenius M, Harper R. Tying in comment sections: The production of meaning and sense on Facebook. The self-explicative organization of communication acts on and through Facebook. Semiotica. 2015(204):121-43.

[30] Meredith J. Analysing technological affordances of online interactions using conversation analysis. Journal of pragmatics. 2017(115):42-55.

[31] Meredith J, Stokoe E. Repair: Comparing Facebook 'chat' with spoken interaction. Discourse Comm. 2014;8(2):181-207.

[32] Housley W, Webb H, Edwards A, Procter R, Jirotka M. Digitizing Sacks? Approaching social media as data. Qualitative Res. 2017;17(6):627-44.

[33] Tolmie P, Procter R, Rouncefield M, Liakata M, Zubiaga A. Microblog analysis as a program of work. ACM Transactions on Social Computing. 2018;1(1):1-40.

[34] Zubiaga A, Liakata M, Procter R, Wong Sak Hoi G, Tolmie P, Masuda N. Analysing how people orient to and spread rumours in social media by looking at conversational threads. PloS One. 2016; 11(3).

[35] Pellettieri J. Negotiation in cyberspace: The role of chatting in the development of grammatical competence. Network-based language teaching: Concepts and Practice. Cambridge, New York: Cambridge University Press; 2000. p. 9-86.

[36] Murphy S. Facebook Finally Adds 'Reply' Option to Comments 2013 [cited 202027 July]. Available from: https://mashable.com/2013/03/25/facebook-replies/. 